\title{
Missed acute isolated peroneal compartment syndrome
}

\author{
Sudesh Ebenezer, MD; William Dust, MD
}

\begin{abstract}
This paper outlines 3 cases of acute isolated peroneal (lateral) compartment syndrome following exertion, minor trauma or overuse. Compartment syndromes are usually associated with crush injuries or fractures; they are an uncommon development following minor trauma or overuse. In acute isolated peroneal compartment syndrome the diagnosis is often delayed, resulting in permanent impairment. Persistent or worsening pain following a minor injury or overuse is typical, and the initial physical findings are often nonspecific, although swelling and tenderness out of proportion to the described injury are common. Marked increase in pain with passive inversion and dorsiflexion of the ankle should suggest the diagnosis. In cases that present late or where the diagnosis is initially missed, there is often a common peroneal nerve palsy. As with all compartment syndromes, prompt diagnosis and surgical decompression is necessary to prevent permanent impairment.
\end{abstract}

Key words: Peroneal compartment syndrome

RÉSUMÉ

Le présent article dresse les grandes lignes de trois cas isolés et aigus de syndrome de la loge péronière (latérale) à la suite d'un effort, d'un traumatisme mineur ou d'un usage abusif. Ce syndrome est généralement associé à une blessure par écrasement ou à une fracture et est inhabituel dans le cadre d'un traumatisme mineur ou d'un usage abusif. Dans ces cas, le diagnostic est retardé, entraînant un handicap permanent. Une douleur persistante ou qui empire à la suite d'une blessure mineure ou d'un usage abusif est typique et les constatations physiques initiales sont souvent non spécifiques, bien que l'œdème et la sensibilité au toucher hors de proportion par rapport à la blessure décrite soient couramment rencontrés. Une exacerbation de la douleur à l'inversion passive et à la dorsiflexion de la cheville devrait permettre d'évoquer le diagnostic. Dans les cas où la visite à l'urgence a été retardée ou encore où le diagnostic initial a été manqué, on retrouve souvent une paralysie du nerf péronier. Comme pour tous les syndromes de la loge, un diagnostic rapide et une décompression chirurgicale sont nécessaires afin d'éviter un handicap permanent.

\section{Introduction}

Lower extremity compartment syndromes are a well recognized occurrence, usually associated with a crush injury or fracture. Acute isolated peroneal (lateral) compartment syndrome following exertion or minor trauma is uncommon, represented in the literature by single case reports or small series. We present 3 cases occurring over a 10 -year period in a busy tertiary hospital emergency department (ED). These cases were identified from the orthopedic surgeons' databases because the orthopedics service is consulted for compartment syndromes. In addition, we performed a PubMed search for the terms peroneal and lateral compartment syndrome and reviewed the appropriate papers.

\section{Case reports}

\section{Case 1}

A 39-year-old male who had suffered from shin splints for many years developed bilateral "shin splints" while playing

Division of Orthopaedics, University of Saskatchewan, Saskatoon, Sask.

Received: Jan. 14, 2002; final submission: Apr. 18, 2002; accepted: May 4, 2002

This article has been peer reviewed. 
tennis. Shortly after the game his right leg pain resolved as usual, but the left leg became more painful. He was seen in the ED that evening complaining of severe lateral and anterior leg pain. On examination the anterolateral leg was tense and tender. There was no calf tenderness, and he was able to actively plantar flex and dorsiflex the ankle, although these movements were limited by pain. Pain with passive motion was not commented on, nor was a neurovascular exam documented. He was discharged with analgesics.

Two days later he returned with persistent and increasing pain. On examination, there was marked tenderness and swelling over the lateral compartment. Motor power was $0 / 5$ in the anterior and lateral compartment musculature, and sensation was diminished in the deep and superficial peroneal nerve distributions. Active plantar flexion of the ankle was present but limited by pain. Passive ankle motion, particularly inversion with dorsiflexion, was painful. Pedal pulses were present, and capillary filling over the leg and foot was normal.

A clinical diagnosis of compartment syndrome was made, and he was taken to the operating room for urgent lateral and anterior fasciotomies. The peroneus longus and brevis muscles were necrotic and required complete excision. Because lateral and anterior compartment syndromes commonly coexist, and because there was paralysis of the anterior compartment muscles, an anterior compartment fasciotomy was also performed, revealing no ischemic damage.

Postoperatively, the patient had a persistent common peroneal nerve palsy with foot drop and required an ankle-foot orthosis for ambulation. By 6 months, he had recovered $4 / 5$ strength of his ankle and toe dorsiflexors, and ankle eversion strength was $2 / 5$. There was persistent decreased sensation on the dorsum of the foot and the first web space. He was able to walk without the orthosis; however, he required a brace for tennis and complained of persistent ankle instability when walking on uneven ground.

\section{Case 2}

A 28-year-old police officer sustained an inversion injury to his right ankle while playing soccer. He initially had mild pain; he was able to weight bear but unable to continue playing. That evening he presented to the ED complaining of pain in the leg and burning in the foot. On examination, his ankle was tender with decreased range of motion, and the mid-fibular region was also tender and swollen. Pain with passive motion was not documented, nor was a neurovascular exam. He was discharged with symptomatic treatment.

Two days later he returned with excruciating pain in the leg and numbness in the foot. On examination there was swelling and tenderness of the lateral compartment. Motor power of the anterior and lateral compartment musculature was $0 / 5$, and there was decreased sensation in the deep and superficial peroneal nerves. Passive ankle motion, particularly inversion with dorsiflexion, was painful. Pedal pulses were present, and capillary filling over the leg and foot was normal.

A clinical diagnosis of compartment syndrome was made, and he was taken to the operating room for urgent lateral and anterior fasciotomies. Findings included a tense lateral compartment with viable peroneus longus muscle. The peroneus brevis, necrotic with a tear across its origin, was completely excised. The anterior compartment was not tense, and the musculature was normal.

Postoperatively, the patient had a persistent common peroneal nerve palsy with foot drop, requiring an ankle-foot orthosis for ambulation. Nine months after discharge there was residual hypoesthesia on the dorsum of the foot, but he had recovered most of his strength, no longer required the orthosis, and had resumed all activities including running.

\section{Case 3}

A 33-year-old horse trainer struck her right leg against a rail wall while riding. Initially she felt the injury was minor, but as the day progressed she developed increasing leg pain. She was seen in the ED that evening complaining of extreme right leg pain. On examination the leg was tender over the posterior, anterior and lateral aspects. Pedal pulses were present; however, ankle motion, strength and neurological examination were not documented. She was discharged home with symptomatic measures. Within 48 hours, she returned to the ED and was again discharged.

She returned for a third ED visit on the third day post injury complaining of increased pain unrelieved by analgesics. Her right leg was swollen and tender over the anterior and lateral compartments, and motor power was $0 / 5$ in these muscles. There was decreased sensation in the deep and superficial peroneal nerves. All passive motions of the ankle and toes were very painful. Active ankle plantar flexion and inversion were present but weak due to pain. The pedal pulses were present, capillary filling of the skin of the leg and foot was normal. Compartment pressures were not measured because the diagnosis was obvious.

As all ankle movements were painful, suggestive of involvement of more than just the lateral compartment, she underwent 4-compartment fasciotomy of her right leg. The lateral compartment musculature was ischemic but not necrotic. The muscles of the anterior and posterior compartments were normal.

Four weeks following discharge she was able to mobilize slowly without assistance. Ankle dorsiflexior strength 
was $4+/ 5$, extensor hallucis longus $0 / 5$, extensor digitorum longus $1 / 5$. Unfortunately, her ankle eversion strength was not recorded. She still had decreased sensation in the first web space of her foot although it had improved considerably. She was lost to further follow-up.

\section{Discussion}

\section{Anatomy}

The leg is divided into 4 non-compliant closed spaces or compartments demarcated by the tibia, fibula, interosseous membrane, intermuscular septa and overlying fascia. The anterior compartment contains the deep peroneal nerve and 3 major muscles: tibialis anterior, extensor hallucis longus and extensor digitorum longus. The lateral compartment contains the common peroneal nerve and its superficial branch and the peroneus longus and brevis muscles. The deep posterior compartment contains the tibial nerve and the tibialis posterior, flexor hallucis longus and flexor digitorum longus muscles. The superficial posterior compartment contains the sural nerve and the gastrocnemius and soleus muscles.

Compartment syndromes associated with tibia fractures most frequently involve the anterior and deep posterior compartments. ${ }^{1}$ Exercise-induced compartment syndromes most frequently involve the anterior compartment. ${ }^{2}$ In these 3 cases the compartment syndromes were isolated to the lateral compartments.

\section{Pathophysiology}

Normal resting compartment pressures range from $0-8$ $\mathrm{mm} \mathrm{Hg}$. Compartment syndromes occur when the pressure within a compartment rises above the closing pressure of the capillaries, creating ischemia of the nerve and muscles. ${ }^{3}$ In normotensive patients this occurs when the compartment pressure exceeds $30-40 \mathrm{~mm} \mathrm{Hg}$ or rises to within 10 $\mathrm{mm} \mathrm{Hg}$ of the diastolic blood pressure. ${ }^{1}$ Injured muscle is more susceptible, and ischemia may occur when the diastolic pressure rises within $20 \mathrm{~mm} \mathrm{Hg}$ of the diastolic blood pressure. ${ }^{1}$ More important than the actual compartment pressure is the difference between systemic blood pressure and compartment pressure because this difference correlates with ongoing capillary blood flow. Irreversible loss of muscle function may occur after as little as 4 hours of total ischemia and is likely after 8 hours. Irreversible nerve changes usually occur after 8 hours of total ischemia. ${ }^{1}$

\section{Etiology}

Anything that increases the contents of a compartment or restricts the volume of a compartment may lead to a compartment syndrome. ${ }^{3}$ Extremity trauma is associated with hematoma formation, cellular swelling and increased capillary permeability, resulting in further swelling. Ischemia compromises capillary integrity, aggravates tissue edema, increases compartment pressure and worsens ischemia. ${ }^{1,4}$ Exercise and overuse increase muscle volume and compartment pressure, predisposing to compartment syndrome. In addition, ischemic muscle swells and fluid shifts into the interstitial space, further increasing compartment pressure. ${ }^{4}$ Overuse-related compartment syndromes have been reported in poorly conditioned individuals, high performance athletes and seasoned military personnel. ${ }^{5,6}$

\section{Diagnosis}

Clinical diagnosis is often difficult because compartment syndromes develop at different rates and are frequently associated with other painful conditions. Despite this, clinical findings are central to diagnosis. Pain out of proportion to the associated condition is typical, and sensory or motor symptoms may occur. Physical findings include pain and weakness with active contraction of the muscles in the involved compartment, pain with gentle passive stretching of the muscles in the compartment, decreased sensation (especially 2-point discrimination or light touch) in the distribution of the nerve traversing the compartment, and tenseness and tenderness of the compartment. ${ }^{1,3}$ Because it is uncommon for compartment pressure to rise above arterial pressure, pedal pulses and distal capillary filling are usually normal. Pulselessness and diminished capillary filling are, therefore, more likely to be due to an arterial injury than a compartment syndrome.

The patients whose cases are presented here all had increasing pain that was severe enough to provoke ED visits. One complained of burning pain in his foot, suggesting nerve ischemia, and all 3 developed sensory and motor findings. Clinical documentation was poor in all 3 cases, but swelling and tenderness over the involved compartments were common features. Unfortunately, all 3 patients developed classic findings of compartment syndrome with common peroneal nerve palsy prior to diagnosis. Case 1 was related to overuse. This man had a history of "shin splints," which may in fact have represented recurrent exercise-induced compartment syndromes that finally passed the point of spontaneous resolution. Cases 2 and 3 were caused by minor injuries associated with hematoma and swelling.

\section{Compartment pressure measurement}

Several techniques are available to measure compartment pressure. Some are less consistent or give systematically higher pressure readings, so the interpretation of compartment pressure depends on the technique used. ${ }^{7}$ The onset of 
ischemia occurs at different pressures in different patients; consequently there is no single critical pressure value above which decompression is necessary, although pressures over $30 \mathrm{~mm} \mathrm{Hg}$ should be considered significant. The difference between the diastolic blood pressure and compartment pressure is more useful, and a compartment pressure within $30 \mathrm{~mm} \mathrm{Hg}$ of the diastolic blood pressure should be considered indicative of a compartment syndrome. ${ }^{7.8}$ Compartment pressure measurements are most useful in cases where the clinical examination is uncertain. In the cases presented, the diagnosis of compartment syndrome was not initially considered and compartment pressures were not measured. If they had been measured the diagnosis would likely have been made earlier. In each case, when the patients returned to the ED their diagnosis was obvious and pressure measurements were not required.

\section{Treatment}

The treatment of compartment syndrome is surgical decompression by fasciotomy. Functional outcome is directly related to the timeliness of decompression, making indecision and diagnostic delay costly. ${ }^{9}$ If compartment syndrome is suspected but the findings - including compartment pressures - are equivocal, re-examination every 30 to $60 \mathrm{~min}$ utes is warranted. In such cases, restrictive circumferential dressings or casts should be released but not necessarily removed and the limb should be placed at heart level but not above because elevation will reduce the limb's blood pressure and worsen ischemia. ${ }^{3}$ Increasing pain or progression of physical findings is indicative of a compartment syndrome. The results of the examinations should be clearly documented because missed compartment syndromes frequently result in litigation that is difficult to defend.

\section{Complications}

Diagnostic delays are common ${ }^{10-15}$ and often lead to permanent impairment, as illustrated in the cases described here. In patients with peroneal compartment syndrome, peroneal muscle damage leads to weakness and instability of the hindfoot. Partial recovery of common peroneal nerve function usually occurs, but persistent sensory loss is common. ${ }^{10-13}$

\section{Conclusion}

Early peroneal compartment syndromes are difficult to differentiate from minor injuries. Pain, swelling and tenderness out of proportion to the injury are common, as is excessive pain with active and passive motion, although the latter may be difficult to interpret because of variability in patient pain tolerance. Diagnostic delays may lead to mus- cle necrosis, common peroneal nerve palsy and permanent disability; therefore, a high index of suspicion is critical, and the onus is on the first physician who sees the patient to consider the diagnosis. Compartment pressure measurement is often diagnostic, but in unclear cases patients should have the affected limb elevated to heart level and be re-evaluated frequently. When the diagnosis is clear, prompt surgical referral is mandatory.

\section{Competing interests: None declared.}

\section{References}

1. Whitesides TE Jr, Heckman MM. Acute compartment syndrome: update on diagnosis and treatment. J Am Acad Orthop Surg 1996;4:209-18.

2. Reneman R. The anterior and lateral compartmental syndrome of the leg due to intensive use of muscles. Clin Orthop 1975;113:69-80.

3. Matsen FA III. Compartmental syndrome: an unified concept. Clin Orthop 1975;113:8-14.

4. Rorabeck CH, MacNab I. The pathophysiology of the anterior tibial compartmental syndrome. Clin Orthop 1975;113:52-7.

5. Lipscomb AB, Ibrahim AA. Acute peroneal compartment syndrome in a well conditioned athlete: report of a case. Am J Sport Med 1977;5:154-7.

6. Blasier D, Barry RJ, Weaver T. Forced march-induced peroneal compartment syndrome: a report of two cases. Clin Orthop 1992;284:189-92.

7. Watson JT. Compartment syndrome. In: Orthopedic Knowledge Update 6. Rosemont (IL): American Academy of Orthopaedic Surgeons; 1999. p. 530-1.

8. McQueen MM, Court-Brown CM. Compartment monitoring in tibial fractures: the pressure threshold for decompression. J Bone Joint Surg [Br] 1996;78:99-104.

9. Matsen FA III, Winquitst RA, Krugmire RB Jr. Diagnosis and management of compartmental syndromes. J Bone Joint Surg [Am] 1980;62:286-91.

10. Davies JAK. Peroneal compartment syndrome secondary to rupture of the peroneus longus: a case report. J Bone Joint Surg [Am] 1979;61:783-4.

11. Nicholson P, Devitt A, Stevens M, Mahalingum K. Acute exertional peroneal compartmental syndrome following prolonged horse riding. Injury 1998;29:643-4.

12. Edwards PW. Peroneal compartment syndrome: report of a case. J Bone Joint Surg [Br] 1969;51:123-5.

13. Arancio O, Bongiovanni LG, De Grandis D. Acute peroneal compartment syndrome: report of a case. Eur Neurol 1985;24:69-72.

14. Atkinson DR, Krause BL. Acute peroneal compartment syndrome [letter]. N Z Med J 1984;97:740.

15. Goodman MJ. Isolated lateral-compartment syndrome. Report of a case. J Bone Joint Surg [Am] 1980;62(5):834.

Correspondence to: Dr. W. Dust, Division of Orthopaedics, University of Saskatchewan, Royal University Hospital, 103 Hospital Dr., Saskatoon SK S7N 0W8; 306 966-8199, fax 306 966-8196, dust@duke.usask.ca 